Unfallchirurg 2014 • 117:678-678

DOI 10.1007/s00113-013-2537-4

Online publiziert: 15. August 2014

(c) Springer-Verlag Berlin Heidelberg 2014

P. Biberthaler ${ }^{1} \cdot$ M. van Griensven ${ }^{2}$

${ }^{1}$ Klinik und Poliklinik für Unfallchirurgie, Klinikum rechts der Isar, Technische Universität München

${ }^{2}$ Experimentelle Unfallchirurgie, Klinik und Poliklinik für Unfallchirurgie, Klinikum rechts der Isar, Technische Universität München

\title{
Biochemische Marker nach Trauma
}

Außer der Messung von Proteinen

Jedes Trauma führt zu einer Zerstörung von Zellen und einer Aktivierung des Immunsystems. Beide Vorgänge führen da$\mathrm{zu}$, dass bestimmte biochemische Molekülen in der Zirkulation gelangen können. Die Moleküle, die von den zerstörten Zellen ausgehen, sind Thema im Beitrag über das Schädel-Hirn-Trauma, wo sie zur Diagnostik und Prognoseeinschätzung herangezogen werden können. Dies kann neben der normalen klinischen und bildgebenden Diagnostik sehr hilfreich sein. Sie können auch eine Hilfestellung in der Entscheidung zur Bildgebung leisten.

\section{》) Jedes Trauma führt zu einer Zerstörung von Zellen und einer Aktivierung des Immunsystems}

Des Weiteren können diese Moleküle, zu denen auch die „danger associated molecular patterns" (DAMP) gehören, das Immunsystem stimulieren. Manche Patienten reagieren sehr stark, andere weniger stark. Außerdem besteht eine Abhängigkeit mit der Schwere des Traumas. Zytokine sind Botschaftermolekülen des Immunsystems und können in der Zirkulation nachgewiesen werden. Die beiden Artikel bezüglich Polytrauma in Erwachsenen und Kindern beschreiben den heutigen Stand der klinischen Forschung im Hinblick auf Nützlichkeit für Prognose und Auftreten von posttraumatischen Komplikationen. Außerdem können Zytokine für die Stratifizierung von Patienten herangezogen werden und hilfreich bei der Bestimmung des Zeitpunkts für die sekundäre Operation sein. können auch die Messenger-RNA aus den Zellen wichtige Marker bei Polytraumapatienten darstellen. Sie werden frühzeitig transkribiert und können zur Translation in die entsprechenden Proteine führen. Dies wird im ersten Beitrag thematisiert.

Wir hoffen, dass diese Arbeiten eine Hilfestellung zur biochemischen Diagnostik bei Traumapatienten sein können. Je besser wir über die Vorgänge in unseren Patienten Bescheid wissen, desto mehr können wir eine maßgeschneiderte, personalisierte Therapie anbieten.

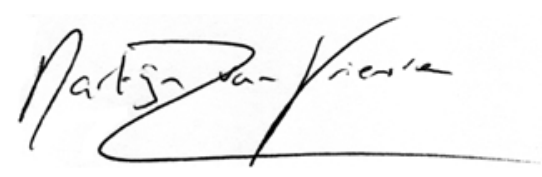

M. van Griensven

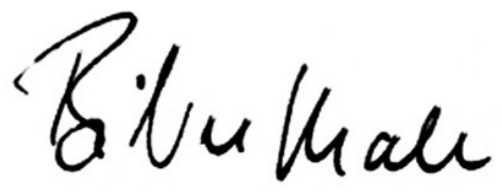

P. Biberthaler

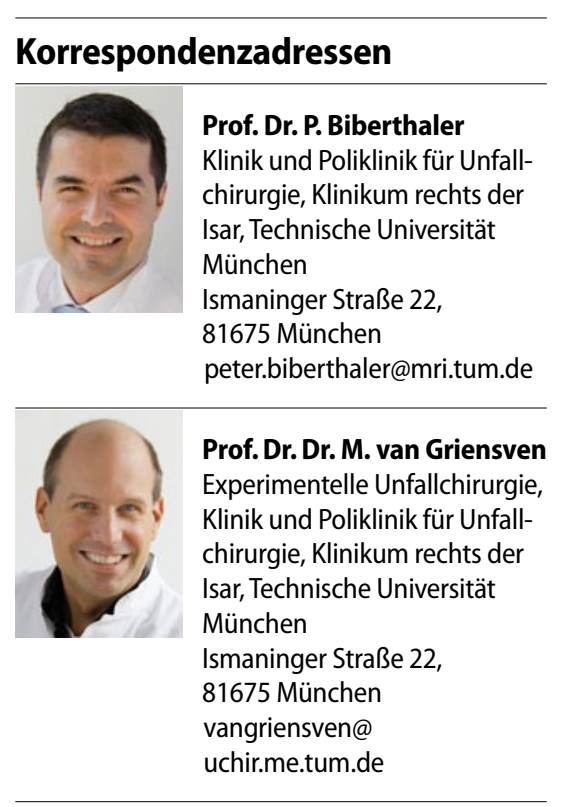

Interessenkonflikt. P. Biberthaler und $M$. van Griensven geben an, dass kein Interessenkonflikt besteht. 